\title{
Soft Magnetic Properties in Bulk Permalloy Alloys Fabricated by a Warm Consolidation
}

\author{
J. FÜZer ${ }^{a}$, P. KolláR ${ }^{a}$, D. OlekšÁKová ${ }^{b}$ AND S. Roth ${ }^{c}$ \\ ${ }^{a}$ Institute of Physics, Faculty of Sciences, P.J. Šafárik University \\ Park Angelinum 9, 04154 Košice, Slovakia \\ ${ }^{b}$ Department of Applied Mathematics, Faculty of Mechanical Engineering \\ Technical University in Košice, Letná 9, 04200 Košice, Slovakia \\ ${ }^{c}$ IFW Dresden, Helmholtzstr. 20, Postfach 270016, 01069, Dresden, Germany \\ Soft magnetic properties of bulk NiFe and NiFeMo alloys consolidated \\ by hot compaction were studied. During annealing the compacts residual \\ stresses diminish by relaxation and soft magnetic properties improve. The \\ lowest coercivity of bulk NiFe and NiFeMo alloys are 11.0 and $11.2 \mathrm{~A} / \mathrm{m}$, \\ respectively, while the total losses are 1.81 and $1.42 \mathrm{~W} / \mathrm{g}$ at $f=10 \mathrm{kHz}$ and \\ $B_{\max }=0.2 \mathrm{~T}$.
}

PACS numbers: 75.50.Bb, 81.20.Ev, 75.60.Ej

\section{Introduction}

The NiFe alloys are the most versatile from all the known soft magnetic materials. The highest permeability characterizes the alloys with the nominal composition $\mathrm{Ni}_{81} \mathrm{Fe}_{19}$ (wt\%) (often called permalloys). This high value derives from the simultaneous disappearance of magnetostriction and crystal anisotropy [1]. Supermalloy $\mathrm{Ni}_{79} \mathrm{Fe}_{16} \mathrm{Mo}_{5}$ has an improved loss characteristic over permalloy materials, which target a higher operating frequency.

Mechanical alloying is a useful powder processing technique that can produce a variety of equilibrium and non-equilibrium alloy phases [2]. Some researches concerning $\mathrm{Ni}-\mathrm{Fe}, \mathrm{NiFeMo}$ powders system produced by mechanical alloying were reported $[3,4]$. Full density nanograined $\gamma-\mathrm{Ni}-\mathrm{Fe}$ bulk material was successfully fabricated by high pressure compaction and pressureless sintering of $\gamma-\mathrm{Ni}-\mathrm{Fe}$ nanoagglomerate powders [5]. In addition to our previous study on $\mathrm{Ni}-\mathrm{Fe}$ [6] and on NiFeMo [7] we have developed a new research on the preparation of the bulk supermalloy by hot consolidation. 


\section{Experimental}

The $\mathrm{Ni}_{81} \mathrm{Fe}_{19}$ (wt.\%) alloy was produced by melt spinning and broken ribbon was hot compacted in order to prepare bulk material. It was impossible to prepare ribbons of $\mathrm{Ni}_{79} \mathrm{Fe}_{16} \mathrm{Mo}_{5}$ (wt.\%) alloy that is why the sample was in the form of swarfs (approximately $0.1 \mathrm{~mm}$ thick) prepared from the ingot. The cryomilling of sample NiFeMo was performed in liquid nitrogen in the planetary ball mill (RETSCH PM4000, BPR 6:1, $180 \mathrm{rpm}$ ) in Ar atmosphere. All the samples were consolidated at $800 \mathrm{MPa}$ for $5 \mathrm{~min}$ at various temperatures into cylinders with outer diameter $10 \mathrm{~mm}$ and thickness $3 \mathrm{~mm}$.

The DC coercivity of compacts was measured by a Förster Koerzimat. An axial hole with diameter of $5 \mathrm{~mm}$ was drilled into the compacted disc, which produced ring samples and we have prepared coils with number of primary turns 20 and number of secondary turns 20 for AC (AMH 401 POD WALKER) measurement. The data presented here are relative to different compositions, one corresponding to a $\mathrm{Ni}_{81} \mathrm{Fe}_{19}$ and the other corresponding to a $\mathrm{Ni}_{79} \mathrm{Fe}_{16} \mathrm{Mo}_{5}$, prepared with the two previous methods:

- NiFe sample - broken NiFe ribbon consolidated at $600^{\circ} \mathrm{C}$,

- sample $A$ - NiFeMo swarfs milled for $1 \mathrm{~h}$, consolidated at $500^{\circ} \mathrm{C}$,

- sample $B$ - NiFeMo swarfs milled for $1 \mathrm{~h}$, consolidated at $600^{\circ} \mathrm{C}$,

- sample $C$ - NiFeMo swarfs milled for $100 \mathrm{~h}$, consolidated at $500^{\circ} \mathrm{C}$,

- sample $D$ - NiFeMo swarfs milled for $100 \mathrm{~h}$, consolidated at $600^{\circ} \mathrm{C}$,

- sample $E$ - NiFeMo swarfs milled for $100 \mathrm{~h}$, consolidated at $700^{\circ} \mathrm{C}$.

The compacts were annealed at temperatures between 700 and $1100^{\circ} \mathrm{C}$ for $1 \mathrm{~h}$ in Ar atmosphere.

\section{Results}

The influence of mechanical milling on structure and magnetic properties of NiFe and NiFeMo powder were reported elsewhere [7]. The FeNi $\mathrm{Fi}_{3}$ phase $\left(T_{\mathrm{C}}=\right.$ $550^{\circ} \mathrm{C}$ ) was created as major phase and minor $\mathrm{NiO}, \mathrm{Fe}_{3} \mathrm{O}_{4}$ phases for $\mathrm{NiFe}$ sample. The mechanical milling of NiFeMo alloy causes the creation $\mathrm{FeNi}_{3}$ phase and minor phase with higher content of Fe with $T_{\mathrm{C}}=650^{\circ} \mathrm{C}$.

The DC coercivity decreases with increasing annealing temperature, reaching a minimum value $(11.0$ and $11.2 \mathrm{~A} / \mathrm{m})$ for $1100^{\circ} \mathrm{C}$ for $\mathrm{NiFe}$ and NiFeMo sample $B$, respectively. This DC coercivity of the present permalloy and supermalloy bulk materials are comparable to those in the form of thin sheet. The value of $H_{\mathrm{C}}$ depends mostly on the surface and volume pinning of magnetic domain walls. The contribution to $H_{\mathrm{C}}$ due to volume pinning results from the presence of internal stress and pores. This contribution is proportional to the product of saturation magnetostriction and the amplitude of stress fluctuations [8].

Figure 1a, b shows the dependence of the AC total losses on frequency for as pressed NiFeMo samples and heat treated samples, respectively. The five curves shown are for samples of $A, B, C, D$, and $E$. From these figures it is clear 

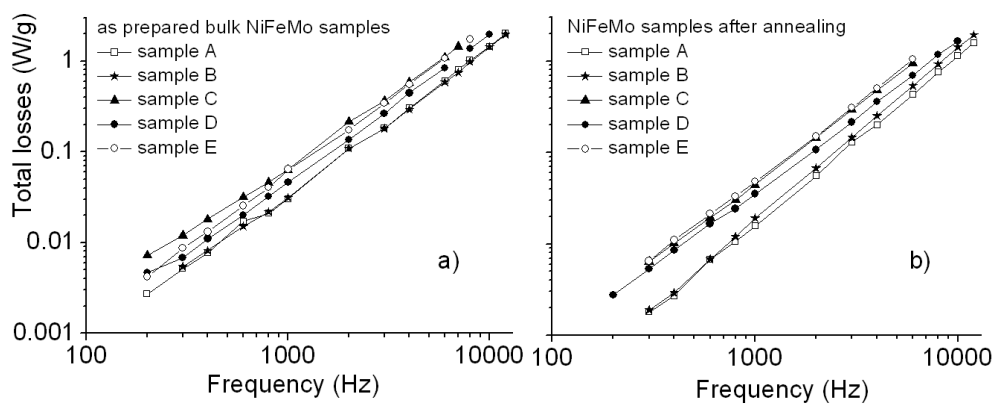

Fig. 1. Frequency dependence of the total losses for (a) as prepared NiFeMo, (b) annealed $\left(1100^{\circ} \mathrm{C}\right) \mathrm{NiFeMo}$ bulk samples.

that increasing the milling time increases the total losses. Annealing decreases the total power losses in our alloy by approximately a factor 2 . Results showed that the NiFeMo sample $A$ compacted at $800 \mathrm{MPa}$ and $600^{\circ} \mathrm{C}$ with following heat treatment at $1100^{\circ} \mathrm{C}$ had the lowest total losses and coercivity in comparison with other samples. These properties are related to the lower porosity, higher density and lower residual stresses of the mentioned sample.

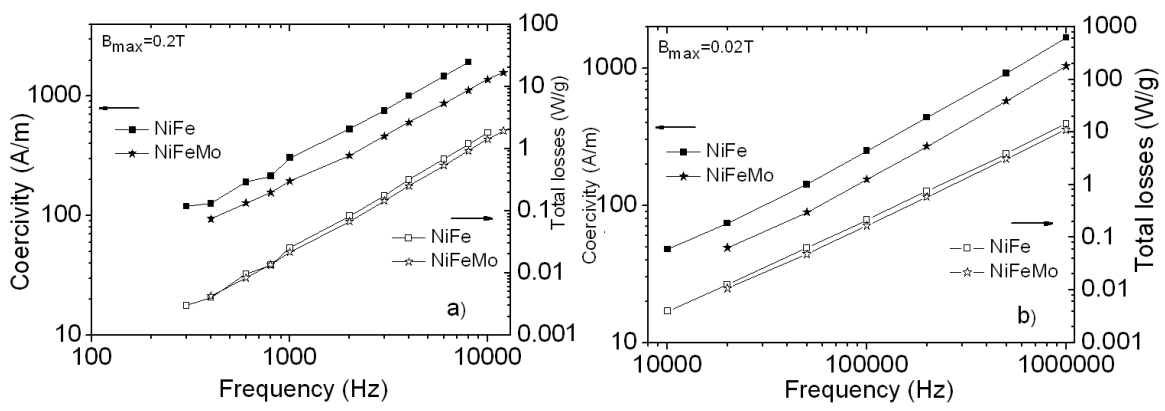

Fig. 2. Frequency dependence of the AC coercivity and total losses for NiFe sample and NiFeMo sample $E$ for (a) $B_{\max }=0.2 \mathrm{~T}$, (b) $B_{\max }=0.02 \mathrm{~T}$.

Figure 2 shows the core losses and the coercivity as a function of frequency for NiFeMo sample $B$ and selected NiFe sample (the best sample from our previous investigations [6]) for different values of the flux density $B_{\max }$. The behaviour is similar; regarding the nature of the addition element Mo. Supermalloy $\mathrm{Ni}_{79} \mathrm{Fe}_{16} \mathrm{Mo}_{5}$ has better characteristics over $\mathrm{Ni}_{81} \mathrm{Fe}_{19}$ sample. This sample shows higher total losses as compared to those of supermalloy metals in the form of thin sheet. It is caused by the shape of our samples, which leads to the higher eddy current losses as a part of the total core losses. 


\section{Conclusion}

We have prepared bulk samples in the form of the small cylinders with coercivity down to $11 \mathrm{~A} / \mathrm{m}$. The frequency dependence of magnetic properties is also illustrated and is attributed mainly to the domain wall damping. These materials have more degrees of freedom for tailoring their magnetic properties due to their flexibility in shape and dimensions. Further studies will be undertaken in order to find good compromise between DC and AC magnetic properties and the improvement will be achieved increasing the compacts density.

\section{Acknowledgments}

This work was supported by the Science and Technology Assistance Agency under the contract No. APVT-20-008404 and by the Scientific Grant Agency of the Ministry of Education of Slovak Republic and the Slovak Academy of Science (VEGA 1/4020/07).

\section{References}

[1] G. Heck, Magnetic Materials and Their Applications, Crane and Russak, New York 1972.

[2] C. Suryanarayana, Prog. Mater. Sci. 46, 1 (2001).

[3] V. Hays, R. Marchand, Nanostr. Mater. 7, 411 (1996).

[4] O. Isnard, V. Pop, I. Chicinas, J. Magn. Magn. Mater. 290-291, 1535 (2005).

[5] J.S. Lee, Y.S. Kang, Scr. Mater. 44, 1591 (2001).

[6] P. Kollár, D. Olekšáková, J. Füzer, J. Kováč, S. Roth, K. Polański, J. Magn. Magn. Mater. 310, 2609 (2007).

[7] D. Olekšáková, P. Kollár, J. Füzer, M. Kusý, S. Roth, K. Polanski, J. Magn. Magn. Mater. 316, e838 (2007).

[8] A.H. Morrish, The Physical Principles of Magnetism, Robert E. Krieger Publ. Co., Huntington 1980, Ch. 7. 